\title{
Mobilização Feminista, Violência de Gênero e Práticas Judiciais no Brasil: Reflexões à Luz da Teoria dos Sistemas Sociais ${ }^{1}$
}

Feminist Mobilization, gender violence and judicial practices in Brazil: Reflexions from the Social Systems Theory.

\author{
Ana Paula Sciammarella* \\ Andrea Catalina León Amaya** \\ Patricia Elisa Rivera***
}

\section{Resumo}

A teoria crítica feminista do Direito, no Brasil, aponta o Judiciário como hermético às reivindicações das mulheres, reprodutor dos arquétipos que reforçam a desigualdade de gênero e a discriminação contra as mulheres. A entrada em vigor da lei 11.340/06 (Lei Maria da Penha) fomenta novas reflexões sobre a judicialização dos chamados conflitos de gênero. Dentre os elementos introduzidos pela Lei Maria da Penha, ganha relevância a criação da categoria normativa "violência de gênero". O presente trabalho reflete teórica e empiricamente o manejo dessa nova categoria normativa pelos operadores do sistema de justiça, num contexto de articulação de serviços e de multidisciplinariedade. As contribuições da teoria dos sistemas sociais proposta por Niklas Luhmann iluminam a reflexão sobre as práticas judiciais nesse contexto.

Palavras - chave: Agenda feminista, violência doméstica, violência de gênero, sistema de justiça, teoria dos sistemas sociais.

\footnotetext{
Abstract

The critical feminist theory of law have characterized the Brazilian legal system as refractory with regards to women's demands and as yet another mechanism that upholds

${ }^{1}$ Trabalho elaborado tomando como referência as temáticas abordadas no curso de Teoria do Direito (2012.2) do Programa de Pós-Graduação em Sociologia e Direito (PPGSD) da Universidade Federal Fluminense (UFF), ministrado pelo Prof. Joaquim Leonel de Rezende Alvim.

" Doutoranda do PPGSD-UFF, na linha de pesquisa "Relações de trabalho, direitos sociais e instituições", diplomada no PostítuloDerechos Humanos y Mujeres de (UC) e pesquisadora do Núcleo de Pesquisas sobre Práticas e Instituições Jurídicas (NUPIJ/UFF). E-mail: anapaula.dh@gmail.com.

** Mestra do PPGSD-UFF, na linha de pesquisa "Acesso à Justiça e crítica das instituições político-jurídicas", integrante do Laboratório Fluminense de Estudos Processuais (LAFEP/UFF) e da equipe do projeto de pesquisa "Articulação entre o sistema de justiça e os serviços de educação e responsabilização para homens autores de violência no âmbito da Lei Maria da Penha no Estado do Rio de Janeiro", aprovado e financiado pelo CNPq no âmbito da chamada pública MCTI/CNPq/SPM-PR/MDA № 32/2012, desenvolvido pelo LAFEP/UFF. E-mail: catalinala7@gmail.com.

*** Doutoranda do Programa de Pós-graduação em Ciências Sociais da Universidade Estadual do Rio de Janeiro (PPCIS-UERJ), bolsista CAPES. E-mail: p.elisarivera@gmail.com.
} 
traditional gender archetypes. Recently, the Law 11.340/06 (The Maria da Penha Act) encourages new reflections on legal decisions regarding so-called gender conflicts in Brazil. Influenced by standards laid out in international decrees regarding the women's rights, this Law introduces innovative elements such as the definition of "gender-based violence". This study reflects theoretically and empirically on the role of the judicial system in the application of the Law 11.340/06, and discusses how the category genderbased violence is being used by those pertaining to the legal system. The contributions of Niklas Luhmann's social systems theory are useful to illustrate the understanding of judicial practices and their impact on the realization of the outlooks surrounding efforts focused on the implementation of the Law 11.340/06.

Key-words: Feminist agenda, domestic violence, gender based violence, legal system, social systems theory.

Fecha de recepción: 30 de Julio 2014

Fecha de aprobación: 20 de Octubre 2015 


\section{Introdução e problematização: Lei Maria da Penha, mobilização feminista e foco na atuação do Sistema de Justiça.}

O tema da violência de gênero é de grande relevância para a sociedade e de grande repercussão para o ordenamento jurídico. $O$ debate sobre seus mecanismos de combate no Brasil não é novo. O processo de regulação estatal dos chamados conflitos de gênero tem seu início com a criação das delegacias especializadas de atendimento à mulher, ganhando destaque com a entrada em vigor da Lei $9.099 / 95^{2}$, que possibilitou o encaminhamento desse tipo de demandas aos então Juizados Especiais Criminais.

Sobre esse fenômeno, autoras como Daniele Ardaillon e Guita Debert (1987) e Silvia Pimentel (1998), buscaram relacionar gênero, direito e poder judiciário, dando ênfase na análise do discurso do Judiciário e apontando um tratamento discriminatório dispensado à mulher nas suas declarações como vítimas, nos atos necessários à produção de provas da agressão nos processos judiciais e no conteúdo das decisões judiciais e jurisprudências.

Além disso, a teoria crítica feminista do Direito vem construindo análises que apontam o Judiciário como hermético e refratário às reivindicações das mulheres, reprodutor em suas práticas de arquétipos que reforçam a desigualdade de gênero e a discriminação contra as mulheres colocando o Direito como mais um mecanismo de fixação de gênero, que se observa nas práticas concretas dos operadores da lei, como assinalado por Rosane Reis Lavigne (2009), Carol Smart (2010) e Carmen Hein de Campos (2011).

Em paralelo ao debate acadêmico, a insatisfação do movimento organizado de mulheres quanto ao Poder Judiciário e instituições afins em razão da inadequada resposta fornecida nos casos de violência contra as mulheres, mobilizou o movimento a exigir uma atuação em relação a esse fenômeno social.

Segundo a descrição de Rosane Reis Lavigne (2009), creditava-se a atuação insatisfatória do poder Judiciário à fragilidade do ordenamento jurídico a partir do tratamento legislativo dispensado ao fenômeno, que acabava por fazer com que o Judiciário ratificasse os papéis de gênero e a hierarquia social em suas decisões, especialmente quando os delitos decorrentes desses conflitos passaram a ser tratados como de menor potencial ofensivo, conduzidos pela lei 9.099/95. Ao passo que no cenário internacional a violência contra a mulher consolidava-se em conferências, documentos e convenções como violação de direitos humanos.

A pouca gravidade simbólica, moral e jurídica dada a esses casos de violência, reforçada pela falta de mecanismos específicos para seu tratamento ou de reparação de danos para

\footnotetext{
${ }^{2}$ A Lei 9.099/95 marcou avanços na legislação brasileira ao prever medidas despenalizadoras para os chamados crimes de menos potencial ofensivo, definidos pela lei como aqueles cuja pena máxima não ultrapassasse dois anos. A referida legislação surgiu em um contexto de informalização do poder judiciário para dar conta de conflitos como brigas de vizinhança, violência conjugal e delitos de trânsito, trazendo uma perspectiva minimalista que considera o direito penal como a última ratio, em um discurso de redução do sistema punitivo clássico. Assim, explicado por Carmen Hein de Campos (2003).
} 
os casos -como explicado por Flávia Piovesan e Sílvia Pimentel (2002)-, provocou a mobilização para o uso de estratégias de mobilização legal, ou legal mobilization- termo usado por Michael MacCann (1999) - na esfera internacional, a partir de um caso emblemático apresentado à Comissão Interamericana de Direitos Humanos (CIDH) - o casoMaria da Penha.

O ativismo jurídico transnacional, no período de 1999 a 2002, foi combinado com a mobilização sistemática nas instituições políticas nacionais e na sociedade, conforme a descrição de Débora Alves Maciel(2011). E, quando em 2001 a CIDH decidiu favoravelmente sobre o caso, foi formado um consórcio de organizações feministas para a elaboração de um projeto de lei focado no tratamento jurídico dos casos de violência doméstica contra a mulher, tendo como objetivos fundamentais: afastar a competência dos Juizados Especiais Criminais para os casos de violência conjugal e criar um juízo especializado para apreciação desses casos.

A mobilização do movimento feminista em torno de campanhas para elaboração de uma "Lei Integral de Enfrentamento à Violência Doméstica e Familiar contra as Mulheres" e o apoio ao projeto de lei $n^{\circ} 4559 / 2004$ ganhou força nacional a partir da realização de audiências públicas e debates feministas em todo o país. Recebeu ainda um substitutivo com um conteúdo que abarca uma série de questões trazidas nessas audiências e debates para a confirmação do projeto de lei, tornando-se o Projeto Substitutivo $n^{\circ} 37 / 2006$, que, por fim, foi aprovado pelo Congresso Nacional, transformando-se na Lei 11.340 no ano de 2006, que recebeu simbolicamente o nome de Lei Maria da Penha (LMP).

Diante da aprovação da nova legislação deu-se início a uma nova etapa de mobilizações voltadas para a implementação da lei recém-criada. Nessa nova fase, de maneira diversa ao ocorrido no legislativo, onde houve consenso na sua aprovação, o Judiciário pareceu confirmar a resistência apontada por críticas do direito em relação às questões das mulheres, tendo a nova legislação se tornado objeto de diversas controvérsias jurídicas e críticas acerca da sua constitucionalidade, sobre seu caráter punitivo, além dos questionamentos sobre sua eficácia na resolução deste tipo de conflito.

Esses obstáculos potenciais à implementação da LMP decorrentes das controvérsias jurídicas e normativas, mobilizaram novamente as organizações feministas, para ações de lobby para a adequada aplicação da Lei aos casos de violência e monitoramento das decisões judiciais, culminando na criação de um observatório para acompanhar sua aplicação. Esta mobilização promoveu moções para os tribunais, indicando interpretações para as questões controvertidas, como a questão da necessidade de representação da vítima para o ajuizamento de ação penal e sobre o tratamento dispensado às relações de namoro sob a perspectiva da Lei, culminando com a propositura de uma Ação Direta de Constitucionalidade junto ao STF no ano de $2007^{3}$.

${ }^{3}$ Que contou com o engajamento das ativistas junto ao Judiciário para reforçar a tese sobre a constitucionalidade da legislação e em ações de incidência junto aos tribunais, em uma campanha intitulada 
Todo esse engajamento, em suas diversas etapas - como interpretado pelas feministas críticas do Direito - parecia ter demostrado que tal mudança legislativa funcionou como uma alavanca para o acesso às políticas públicas judiciárias, mas produziu também novos elementos de debate sobre a judicialização das relações sociais e em particular dos chamados conflitos de gênero, a partir da "criação normativa da categoria violência de gênero" que, nos termos de Carmen Hein de Campos e Salo Carvalho (2011), importaria o rompimento "com a tradição jurídica de incorporação genérica da violência de gênero nos tipos penais incriminadores tradicionais" (Campos e Carvalho, 2011, p. 145) e submete à regulação estatal os conflitos decorrentes das "relações íntimas de afeto".

Dessa forma, a nova legislação teria inaugurado um novo paradigma jurídico que, além de retirar da invisibilidade a questão da violência contra a mulher no seu aspecto normativo, buscou implementar uma política judicial com a incorporação da perspectiva de gênero para a administração deste tipo de conflito como medida de busca pela igualdade material entre homens e mulheres, nos termos debatidos por Rios (2012) sobreigualdade e diferença e a partir da compreensão de Nancy Fraser (2001) sobre distribuição e reconhecimento.

O contexto apresentado é fundamental para a compreensão da expectativa depositada pelo movimento feminista no Judiciário, entendido como arena política, instrumentalizada na atualidade através da LMP, como recurso jurídico e político que potencializaria mudanças na dimensão prática da atuação dos operadores do direito, e impactaria também na transformação dos estereótipos de gênero ${ }^{4}$.

O presente trabalho visa discutir, de uma ótica sócio jurídica, alguns dos desafios presentes na compreensão e tratamento dos conflitos que envolvem violência doméstica contra as mulheres, enquanto evidenciam dificuldades próprias da comunicação que vem se impulsionando entre as categorias pertencentes ao sistema jurídico - dentro do qual a LMP se insere - e as categorias sociais e políticas elaboradas, ora no cenário da mobilização social, ora nos setores acadêmicos, em torno da conceituação e gestão dos conflitos de gênero ou da violência de gênero.

Assim, sem uma pretensão de exaustão, consideramos que a perspectiva sistêmica sustentada por Niklas Luhmann (1983 e 1985), ganha pertinência ao oferecer elementos teóricos úteis no exercício de descrição e explicação de tais desafios. Verificamos um processo contínuo de ajuste decorrente da interação entre o sistema social e o subsistema jurídico no qual a LMP emerge, acompanhado da tentativa de conciliar as expectativas

"Compromisso e Atitude pela Lei Maria da Penha - a lei é mais forte".Site da campanha: http://www.compromissoeatitude.org.br/home/pagina-inicial/

4"Os estereótipos de gênero referem-se à construção social e cultural de homens e mulheres, por motivo de suas diferentes funções físicas, biológicas, sexuais e sociais. [...] Entender a forma como o direito encarna e contribui à atribuição de estereótipos de gênero, faz parte do caminho para entender as experiências de inequidade que vivem as mulheres, condicionadas por aquele". (Cook, 2010, 23 e ss.). 
sociais - as do movimento feminista referidas às relações de gênero - com os códigos e processos comunicativos próprios do subsistema jurídico. Nesse sentido, a categoria gênero com suas diversas gramáticas - das ciências sociais e humanas, dos feminismos, do discurso dos direitos humanos, etc. - e sua tradução para o Direito, por ocasião da nova legislação, bem como na atuação dos operadores do sistema de Justiça, constitui o desafio mais visível no fluxo das decisões jurisprudenciais. A reflexão teórica, em diálogo com a análise de decisões jurisprudenciais, será o foco do subtítulo ll do presente trabalho.

Já na abordagem prática da dinâmica observada nos juizados especializados criados pela LMP, identificamos um segundo cenário de ajuste e tradução das mesmas categorias. Assim, no subtítulo III, são trazidos achados significativos do trabalho de campo efetuado durante 2013, visando enxergar a emergência de micropolíticas judiciárias baseadas nos códigos de auto-referenciação dos juizados especializados, bem como os desafios da atuação em rede e da comunicação interdisciplinar idealizadas no texto da LMP.

A pesquisa de campo realizada em 2013 , da qual se utiliza parcialmente o subtítulo III deste artigo, incluiu: (i) a observação das rotinas de trabalho do Juizado de Violência Doméstica e Familiar contra a Mulher (JVDFM) da Comarca de Niterói, no Estado do Rio de Janeiro5; (ii) observação de espaços de diálogo interinstitucional entre diferentes atores do Sistema de Justiça ${ }^{6}$; (iii) entrevistas com Juízes ${ }^{7}$ e outros atores chave; (iv) a leitura de documentos de diretrizes de política judiciária produzidos no âmbito do Tribunal de Justiça do Estado do Rio de Janeiro (TJ-RJ) e do Conselho Nacional de Justiça (CNJ) ${ }^{8}$.

\footnotetext{
${ }^{5}$ A observação efetuada de abril a dezembro de 2013 enfocou: observação participante do trabalho cotidiano do cartório e da equipe técnica multidisciplinar, observação de audiências, acompanhamento dos grupos reflexivos para homens autores de violência doméstica que realiza a equipe técnica multidisciplinar vinculada ao Juizado, leitura dos autos dos processos e entrevistas semiestruturadas aos funcionários da equipe e do cartório.

${ }^{6}$ Para os efeitos da reflexão proposta no presente artigo, salienta-se o observado e registrado em diário de campo, durante o seminário organizado pelo Ministério Público no âmbito da comemoração dos sete anos de entrada em vigor da LMP: Seminário "Questões de gênero e violência: Lei Maria da Penha como foco", realizado no Tribunal de Justiça do Estado do Rio de Janeiro (TJ-RJ), nos dias 23, 26 e 30 de agosto de 2013 (http://www.compromissoeatitude.org.br/questoes-de-genero-e-violencia-a-lei-maria-da-penha-como-foco-riode-janeiro-rj-23-26-e-30-de-agosto/?print=1).

${ }^{7}$ O presente artigo salienta especificamente a entrevista realizada ao ex-Juiz em exercício do JVDFM de Niterói.

8 Destacam-se no caso os seguintes documentos: do TJ-RJ, o documento de "Padronização do Grupo Reflexivo dos Homens Agressores. Uniformização de Procedimentos para Estruturação, Funcionamento e Avaliação dos Grupos Reflexivos com Autores de Crimes de Situação de Violência Doméstica" (consultado em 24 de fevereiro de 2013 no site Web da Escola da Magistratura do Estado do Rio de Janeiro: http://www.emerj.rj.gov.br/revistadireitoemovimento_online/edicoes/ volume14/volume14.pdf), e do (CNJ), o "Manual de Rotinas e Estruturação dos Juizados de Violência Doméstica e Familiar contra a Mulher" (recuperado em 12 de novembro de 2012 no site Web do Fórum Nacional de Juízes de Violência Doméstica e Familiar contra a Mulher: http://www.amb.com.br/fonavid/Documento_Manual\%20Maria\%20da\%20Penha .pdf).
} 


\section{Gênero como categoria... Normativa?}

A construção social do sexo e do gênero, a partir dos debates norte-americanos e franceses ao final dos anos 80, influenciou a academia e, em seguida, o movimento feminista brasileiro. Essa influência fez com que a categoria mulher fosse substituída pela categoria gênero. Para Wânia Pasinato e Cecília MacDowell (2005), essa nova categoria, apesar das divergências sobre sua definição, abre caminho para um novo paradigma nos estudos das questões relativas às mulheres sob uma nova perspectiva que enfatiza na diferença entre o social e o biológico.

A definição de gênero tem como principal referência no Brasil o estudo de Joan Scott (1998), para quem se trata de um elemento constitutivo das relações sociais fundadas sobre as diferenças percebidas entre os sexos. É, ainda, um modo de dar significado às relações de poder. A autora defende o uso do termo como uma categoria histórica e instrumento metodológico, definido, segundo ela, como elemento constitutivo das relações sociais que têm por base as diferenças entre os sexos como forma primária de significação das relações de poder.

Segundo interpretado por Daniel Schroeter Simião (2000), a partir da sua leitura das colocações de Joan Scott, era preciso encontrar conceitos que permitissem diferenciar aquilo que as mulheres tinham de natural, permanente, e igual em todas as épocas e culturas - o sexo - do que por ser socialmente construído, variava de sociedade para sociedade e podia mudar com o tempo - o gênero.

Essa nova perspectiva de análise foi incorporada aos estudos feministas brasileiros ao final dos anos 90, e trouxe significativas alterações às abordagens das pesquisas e debates sobre o tema da violência contra a mulher, tal como, a inserção do tema da vitimização e a análise das dinâmicas dos registros policiais e processos judiciais, a partir da compreensão de que gênero refere-se à construção social do masculino e do feminino e presta-se à análise das relações entre homens e mulheres, como continuam a descrever Wânia Pasinato e Cecília MacDowell Santos (2005).

Além de influir na perspectiva de análise dos estudos sobre o tema, o uso dessa categoria introduziu, ainda, uma nova expressão para o fenômeno da violência contra as mulheres: o termo violência de gênero, como uma categoria mais geral que englobaria a violência doméstica e intrafamiliar, e embora existissem significativas divergências quanto a isso, a expressão foi também usada como sinônimo de violência contra a mulher. A problematização sobre a qualificação do conceito de violência, considerando suas distintas abrangências, foi amplamente debatida por Rifiotis (2008), que afirma que o eleição do termo "violência de gênero", carrega em si uma dimensão política explícita e desejada pelos movimento feministas, base da própria afirmação do caráter político das relações de gênero. 
Isso ocorreu mesmo quando o uso do termo pretendia desnaturalizar a condição da mulher na sociedade. Os distintos usos, como afirmaram Wânia Pasinato e Cecília MacDowell Santos (2005), serviam para apontar a necessidade de melhor precisar os conceitos e diferenças conceituais entre as expressões violência contra as mulheres, violência de gênero, violência conjugal, violência familiar e violência doméstica.

Os reflexos dos debates sobre o uso da categoria gênero foram sentidos também, no cenário político-jurídico. Isso aconteceu, por ocasião do processo de redemocratização e adesão do Brasil a tratados internacionais de direitos humanos que reconheciam a discriminação e a violência contra a mulher como violação de direitos humanos e incorporavam a expressão gênero em seus textos, como foi o caso da Convenção de Belém do Pará que se utiliza daquele termo para a conceituação de violência contra a mulher ${ }^{9}$. Assim, abriu-se a porta para a inserção da perspectiva de gênero na política judiciária brasileira, que se consolida quando da elaboração da Lei Maria da Penha, que cria definitivamente uma normativa específica para a categoria violência de gênero, como explicitado por Carmen Hein de Campos e Salo Carvalho (2011).

Inspirada pela Convenção de Belém do Pará, a lei conceitua violência como "qualquer ação ou omissão baseada no gênero que lhe cause morte, lesão sofrimento físico, sexual ou psicológico e dano moral ou patrimonial (...)" (Lei 11.340/06, artigo 50). No entanto, restringe a sua aplicação aos casos de violência que ocorrem em ambiente doméstico independente de vínculo familiar -, nas relações familiares ou nas chamadas "relações íntimas de afeto" (Lei 11.340/06, artigo $5^{\circ}$ ). Estas restrições, segundo Wânia Pasinato (2010), se justificam por serem aqueles os contextos e situações em que as mulheres mais sofrem violência e pela contraposição a uma política criminal que coloca a proteção à família em primeiro lugar, deixando em segundo plano a proteção dos direitos individuais, permitindo desta maneira que muitos agressores de mulheres nunca sejam responsabilizados por seus atos.

Empresta sentido a essa análise, a noção de "judicialização das relações sociais" utilizada por Rifiotis (2008), para designar os processos que visibilizam através da ampliação da ação do Estado em áreas de "problemas sociais" como mecanismos de garantia e promoção de direitos. Onde, também se insere a violência de gênero como uma categoria que concernente à equidade de gênero e o acesso à justiça.

Essa conceituação objetiva daria sentido, na perspectiva da teoria dos sistemas sociais de Luhmann, à legislação, selecionando os limites de aplicação da mesma, conforme as fronteiras do próprio sistema jurídico no qual ela emerge, como colocado por Juan Antonio García Amado (2004), além de ilustrar o processo social permanente para a necessária redução da complexidade social, através de comunicações que funcionam como um contínuo "acontecer seletivo" (García, 2004, p. 304) e como "sucessivas

\footnotetext{
${ }^{9} \mathrm{O}$ artigo $1^{\circ}$ da Convenção Belém do Pará expressa: "Para os efeitos desta Convenção, entender-se-á por violência contra a mulher qualquer ato ou conduta baseada no gênero, que cause morte, dano ou sofrimento físico, sexual ou psicológico à mulher, tanto na esfera pública como na esfera privada".
} 
delimitações do possível" (García, 2004, p. 306), implicando na geração de novos subsistemas.

Nessa linha, poder-se-ia afirmar que o processo de edição da LMP importou o desencadeamento de processos comunicativos, de ajuste e de filtragem, em face do aumento da complexidade do meio social: ao passo que novos códigos foram se construindo nas ciências sociais para descrever, simplificar e explicar certas relações, condições e fatos, resultando na elaboração - no caso - da categoria gênero, um espectro maior de irritações e excitações,vieram a atingir o sistema jurídico, provocando por sua vez, processos internos de redução e delimitação, que se expressam nas decisões judiciais.

Tal como descrito na exposição de motivos da LMP, o conceito gênero é basilar para sua compreensão, já que "a violência intrafamiliar expressa dinâmicas de poder e afeto, nas quais estão presentes relações de subordinação e dominação" ${ }^{10}$. Desta forma, todo o processo de construção de um código de relação entre os sexos é levado para o Direito para que nele sejam administrados os conflitos decorrentes dessas relações.

O Direito passa, portanto, a operar com essa categoria na construção das decisões que dizem respeito à competência dos Juizados de Violência Doméstica e Familiar contra a Mulher, que delimitam a aplicação da Lei aos casos que neles se apresentam. As decisões judiciais funcionariam, desta forma, como ferramenta comunicacional de construção e fixação de um sentido delimitador, visando à estabilização de expectativas para "tornar previsíveis as comunicações que se sigam de cada comunicação dentro do sistema" (García, 2004, p. 312), reforçando um esquema disjuntivo de pertencimento ou não pertencimento ao sistema jurídico.

Contudo, a inserção da categoria gênero no sistema jurídico não importaria a mudança automática do sistema nem sua adaptação aos códigos dos outros sistemas que o irritam. Tratar-se-ia só da dinamização da sua capacidade auto-constitutiva e auto-referenciada, usando da sua "sensibilidade seletiva" para determinar aquilo que pode ser tomado ou não, aquilo que entra ou fica de fora (García, 2004, p. 315-317). Tal como expressado na decisão de um caso em que o desembargador argumentou:

[...] é necessário perquirir em cada caso concreto se as relações, tidas como afetivas ou denotadas como sexuais se inserem no contexto previsto na legislação em comento, não se perdendo de vista que o termo relação íntima de afeto não deve ser ampliado de molde a albergar um relacionamento passageiro, fugaz ou esporádico, como ocorre na espécie ${ }^{11}$.

\footnotetext{
10 Exposição de motivos $\mathrm{n}^{\circ}$ 016-SPM/PR disponível em: http://www.planalto.gov.br/ccivil 03/Projetos/EXPMOTIV/SMP/2004/16.htm

${ }^{11}$ Embargos infringentes e de nulidade ${ }^{\circ}$ 0376432-04.2008.8.19.0001, 7a Câmara Criminal - TJRJ, Vogal designado para o acórdão: Desembargador: Sidney Roda da Silva, 25 de junho de 2013. Ementa:

“EMBARGOS INFRINGENTES. Sustentação de incompetência do Juizado da Violência Doméstica e Familiar. Sem adentrarmos ao mérito da ação penal, temos que, pelo menos em tese, a imputação de agressão realizada por
} 
Neste mesmo sentido, outra decisão sobre o conflito de competência afirma que como não se tratava de uma "relação afetiva, familiar ou doméstica" a aplicação da LMP para esse caso poderia "banalizar sua finalidade", já que não se tratava de "relação íntima de afeto duradoura", devendo o caso, segundo a juíza, ser remetido para a "vara criminal comum":

[...] a proteção conferida às mulheres se justifica em função da maior vulnerabilidade que as mesmas apresentam quando inseridas no âmbito da unidade doméstica da familiar ou numa relação íntima de afeto, constato que na hipóteses sub examine não há elementos aptos que evidenciem qualquer das aludidas situações e que por isso o caso deveria ser julgado por uma 'vara criminal comum' ${ }^{12}$.

Na mesma linha, o que cada sistema recebe de seu meio não é impulso causal sem participação do sistema mesmo, senão uma "ressonância subsequente à produção de uma mudança nesse meio, porém percebida pelo sistema conforme seus próprios códigos" (García, 2004, 317). Aproximando-se desse fenômeno, em outra decisão, os desembargadores buscam aproximar a categoria gênero de outra categoria do direito à qual se associa a ideia de vulnerabilidade - a hipossuficiência -, e neste sentido procuram equiparar gênero à hipossuficiência, afirmando que:

[...] o campo de atuação e aplicação da respectiva lei está traçado pelo binômio hipossuficiência e vulnerabilidade em que se apresenta culturalmente o gênero mulher no conceito familiar, que inclui relações diversas, movidas por afetividade ou afinidade. No entanto, uma simples análise dos personagens do processo, ou mesmo da notoriedade de suas figuras públicas, já que ambos são atores renomados, nos leva a concluir que a indicada vítima, além de não conviver em

um indivíduo contra sua namorada, poderia, dentro do conceito lógico legal, ser tutelada pela Lei Maria da Penha (Lei no 11.340/06). Entretanto, a ratio legis requer sua aplicação contra violência intrafamiliar, levando em conta relação de gênero, diante da desigualdade socialmente constituída. $\mathrm{O}$ campo de atuação e aplicação da respectiva lei está traçado pelo binômio hipossuficiência e vulnerabilidade em que se apresenta culturalmente o gênero mulher no conceito familiar, que inclui relações diversas, movidas por afetividade ou afinidade. No entanto, uma simples análise dos personagens do processo, ou mesmo da notoriedade de suas figuras públicas, já que ambos são atores renomados, nos leva a concluir que a indicada vítima, além de não conviver em relação de afetividade estável como o réu ora embargante, não pode ser considerada uma mulher hipossuficiente ou em situação de vulnerabilidade. Embargos Infringentes que se conhece e no mérito dá-se provimento".

12 Apelação Criminal n ${ }^{0}$ 0042033-61.2009.8.19.0203, 7a Câmara Criminal - TJRJ, Relatora Maria Angélica G. Guerra Guedes, 14 de agosto de 2012. Ementa:

"APELAÇÃO CRIMINAL. Delito de sequestro, lesão corporal e constrangimento ilegal. Decreto condenatório. Inconformismo geral. Ministério público pugna pela condenação do apelante Luiz Henrique nos crimes do art. 129 e 146, ambos do CP. Requer ainda majoração da pena do apelante bruno, com aplicação da agravante do art.62, do cp. ao seu turno, a defesa argui incompetência do juízo; nulidade do processo, com base na súmula 523, do STF; nulidade dadecisão, por infringência ao art.155, do CPP e art.93, ix, da CRFB/88. No mérito, pleiteia a absolvição por insuficiência do acervo probatório, salientando que a prova indiciária não é suficiente à emissão de juízo de censura, sendo certo que a palavra da sedizente vítima era desprovida de qualquer credibilidade. Subsidiariamente, requer a redução da pena e fixação de regime prisional mais brando". 
relação de afetividade estável como o réu ora embargante, não pode ser considerada uma mulher hipossuficiente ou em situação de vulnerabilidade. ${ }^{13}$

A inserção da categoria gênero com uma pretensão de criação de uma nova categoria normativa norteadora da operacionalização do direito nos casos de violência doméstica contra a mulher tem como implicação apenas a irritação do sistema, que é por ele mesmo resolvida: "é o próprio sistema que determina o valor informativo dos dados que assume [...] todo dado do meio é reduzido a um estado simples, que permite expressar em termos simples de afirmação ou negação sua assunção pelo sistema" (García, 2004, p. 318).

Assim, pensar no sistema de justiça como um campo para compreender os usos do termo gênero nas práticas relativas a esse universo nos faz perceber que o próprio Direito atribui ao conceito, novas matizes da sua bagagem conceitual e que desta forma gênero vêm se constituindo, também neste espaço, como objeto de disputa.

Assim, se por um lado, classificar como crime os eventos violentos ocorridos no espaço doméstico e familiar atendeu, inicialmente, às expectativas das feministas,ao deixar de fora as ocorrências envolvendo mulheres no espaço público, essa escolha parece ter contribuído para que a representação da mulher se mantivesse vinculada e definida por seus papéis domésticos e familiares historicamente a elas atribuídos. O que vem sendo utilizado pelo Direito para delimitar a conceituação de gênero em diversas decisões. Os casos mencionados acima parecem reafirmar esses significados tradicionais, circunscrevendo a violência de gênero em um sentido estrito, embora o texto legal tenha ampliado o significado desses espaços para além da violência conjugal.

Se a LMP propõe as relações íntimas entre homens e mulheres como de poder, e a violência contra a mulher como resultante da forma historicamente desigual, em suas decisões os atores do sistema de justiça buscam relacionar o conceito de gênero com categorias já conhecidas pelo universo jurídico tal como a ideia de hipossuficiência.

Dos casos analisados é possível inferir contrastes entre os atores do sistema de justiça que operam a legislação. Considerando o conceito de gênero como emprestado das ciências

${ }^{13}$ Embargos infringentes e de nulidade $n^{\circ}$ 0376432-04.2008.8.19.0001, 7a Câmara Criminal - TJRJ, Vogal designado para o acórdão: Desembargador: Sidney Roda da Silva, 25 de junho de 2013. Ementa:

"EMBARGOS INFRINGENTES. Sustentação de incompetência do Juizado da Violência Doméstica e Familiar. Sem adentrarmos ao mérito da ação penal, temos que, pelo menos em tese, a imputação de agressão realizada por um indivíduo contra sua namorada, poderia, dentro do conceito lógico legal, ser tutelada pela Lei Maria da Penha (Lei no 11.340/06). Entretanto, a ratio legis requer sua aplicação contra violência intrafamiliar, levando em conta relação de gênero, diante da desigualdade socialmente constituída. O campo de atuação e aplicação da respectiva lei está traçado pelo binômio hipossuficiência e vulnerabilidade em que se apresenta culturalmente o gênero mulher no conceito familiar, que inclui relações diversas, movidas por afetividade ou afinidade. No entanto, uma simples análise dos personagens do processo, ou mesmo da notoriedade de suas figuras públicas, já que ambos são atores renomados, nos leva a concluir que a indicada vítima, além de não conviver em relação de afetividade estável como o réu ora embargante, não pode ser considerada uma mulher hipossuficiente ou em situação de vulnerabilidade. Embargos Infringentes que se conhece e no mérito dá-se provimento". 
sociais ao Direito é interessante observar em que medida seu significado transita entre os discursos e as classificações dos operadores que vão a ele dando sentido. Essas classificações conferem a eles o poder social de instituir, marcar fronteiras e hierarquias nos debates sobre o conceito de gênero nos discursos e nas relações dentro do sistema de justiça.

E reconhecer isso não é banal, pois são elementos reveladores da atuação de suas instituições. Não se trata de afirmar que a categoria gênero perca sentido ou funcionalidade no Direito. Pelo contrário, cobra sentido na gestão dos conflitos que envolvem violência, mas trata-se de um sentido definido pelo Direito, mediante seu próprio código de tradução. Assim, é o sistema jurídico que vem a definir agora como funciona a categoria gênero nos casos enquadrados na LMP.

\section{Juizados especializados, rede de atendimento e serviços multidisciplinares: reforço da auto-referenciação do sistema jurídico na gestão dos conflitos de gênero?}

Um outro viés das implicações expostas acima, encontra-se na atuação particular dos juizados especializados criados pela LMP, em face do cenário das políticas públicas para o enfrentamento à violência de gênero, bem como em relação à inserção de equipes multidisciplinares na estrutura daqueles juizados.

O corpo normativo da LMP, rico em diversidade de estratégias de intervenção não resumidas à intervenção judicial, reflete a intencionalidade que impulsionou originariamente a sua edição: a adaptação da legislação interna aos instrumentos internacionais de proteção dos direitos humanos das mulheres, por via da adoção de diferentes medidas que em conjunto conformariam uma política pública integral de enfrentamento à violência baseada no gênero.

Cunharam-se assim, na motivação do projeto de lei, no texto aprovado da lei, nos documentos de política pública, nos diversos relatórios de monitoramento, nas atividades públicas de divulgação da LMP, bem como em textos acadêmicos, expressões de uso recorrente para se referir aos mecanismos de intervenção estatal de efetivação das medidas legais elencadas: atuação em rede, integração, articulação, atenção multidisciplinar e especializada.

Teóricas preocupadas com a interpretação da lei em uma perspectiva jurídico-feminista têm referido esse enfoque de atuação pública:

Dada a amplitude das ações que são previstas na legislação, as condições para sua aplicação incluem mudanças substantivas nas políticas de segurança pública e no judiciário, mas também requerem a integração entre políticas e serviços nas áreas de segurança, justiça, saúde, assistência social, médica, psicológica, entre outras. Ciente dessas complexidades, a Secretaria de Políticas para Mulheres do governo federal, cuidou para que a lei não surgisse como um ato legislativo isolado, criando- 
Ihe apoio no Pacto Nacional de Enfrentamento da Violência Contra as Mulheres (2007) e em outros programas, projetos e políticas do governo federal. (Pasinato, 2011, p. 119-121).

Todavia, fruto do monitoramento da LMP, diversos relatórios vêm sendo produzidos remarcando a ênfase na atuação sob uma orientação de política pública. Assim por exemplo, a Comissão Parlamentar Mista de Inquérito (CPMI) da Violência contra a Mulher ressalta no mais recente relatório (2013), a falta de articulação da rede como um dos principais obstáculos ao enfrentamento à violência contra as mulheres: "Não encontramos integração e interação entre os diversos componentes da rede, além do estabelecimento de procedimentos próprios sem a devida discussão entre os integrantes da rede" (Senado Federal, 2013, p. 631). Ademais recomenda, dentre outros aspectos, "articular a Rede Especializada de Enfrentamento à Violência contra Mulheres, institucionalizando protocolos de serviço e de atendimento, em parceria com as instituições do sistema de justiça e com o movimento de mulheres" (p. 632), bem como "dotar todos os Juizados Especializados de Violência Doméstica e Familiar contra a Mulher de equipes multidisciplinares compostas por funcionários de carreira" (p. 633).

Nesse contexto, chama a atenção o observado no seminário organizado pelo Ministério Público no marco da comemoração dos sete anos de entrada em vigor da LMP, que nos permite dialogar com as reflexões expostas no subtítulo precedente, levando em consideração o discurso dos atores participantes, que aponta para as dificuldades práticas da articulação, num contexto de marcada especialização.

No decorrer das palestras, foi significativo o diálogo promovido entre uma juíza de violência doméstica e uma cientista social, trazendo à tona os desafios do recurso, na atuação pública, à categoria gênero, sua inserção como critério em branco a ser dotado de sentido e operacionalizado pelos juízes na hora de se definir as competências, bem como os limites e modos de tratamento dos conflitos de violência doméstica contra as mulheres. Situação que se reforça em face da coexistência de outros estatutos especializados de proteção a grupos específicos - idosos e infância e adolescência, por exemplo - dando conta da tendência à excessiva especialização normativa.

Da palestra da juíza convidada ${ }^{14}$, intitulada "Competência dos Juizados de Violência Doméstica e Controvérsias", registramos durante a observação de campo o seguinte:

[Com a] criação dos JVDFM não quer dizer que as mulheres estejam sendo mais respeitadas no Judiciário. Nos casos de crimes entre duas mulheres, fica clara a aplicação da LMP se tratando de uma relação homo afetiva. Mas quando é da mãe contra a filha ou entre duas irmãs, seria a LMP ou não? A LMP não explicitou os conceitos de gênero, patriarcado, visão androcêntrica ou sexista... nada. Naqueles casos, não haveria violência baseada no gênero pelo fato de ser definida essa violência como aquela que se comete contra a mulher em função do patriarcado e,

\footnotetext{
${ }^{14}$ Adriana Ramos de Mello, Juíza de Direito - I Juizado da Violência Doméstica e Familiar contra Mulher da Capital, RJ.
} 
em tese, entre duas mulheres não tem essa questão. Para o STF é claro: não aplica a LMP. E no caso das crianças: foi violência baseada no gênero ou na idade? Pelo fato de ser criança ou de ser menina? A interpretação dominante é a primeira e, portanto o caso seria encaminhado para a Vara criminal. O TJ de Santa Catarina tem definido a seu turno que os JVDFM têm competência para conhecerem de crimes dolosos contra a vida até a fase da pronúncia, nos casos de homicídio perpetrado em contexto de violência doméstica. Mas eu discordo. E de fato, eu estou recebendo, por erro, tentativas de homicídio. Onde está escrito que o Tribunal de Júri não pode se valer da LMP?! Pode sim, até decretar medidas protetivas! [...] Quando eu tenho dúvida quanto à violência de gênero, aí eu primeiro escuto a minha equipe técnica.

[...] E vice-versa, nos casos de mulher idosa que sofre violência da sua filha, do filho, da cuidadora, às vezes vão para o JVDFM e ninguém aplica o estatuto do idoso, que tem medidas especializadas, mas que não são consideradas.

A LMP não é para ser estritamente aplicada pelos JVDFM. São leis que devem ser aplicadas independentemente dos juízes. Essa visão fragiliza as leis. Existe uma confusão entre campo jurídico, lugares e lei. O operador do direito é quem está na ponta. Mas ninguém quer aplicar a lei na Vara Criminal. Ou acham que não podem. A LMP não é procedimental nem penal, nem criou crimes, só aumentou algumas penas. Deveria ser aplicada em qualquer vara! Pode ser aplicada e utilizada por outros juízes. Não sei por que isso não ocorre. Tais interpretações são uma forma de fragilizar o sistema todo.

[...] Articulação do Judiciário com a rede é um assunto muito novo. O direito é restrito. Nada toma das ciências sociais. A formação não é interdisciplinar. O juiz não interage com a sociedade. O Juiz deveria sair e conhecer a rede. Não devem se confundir campos teóricos com lugares onde aparecem. As pessoas estão atravessadas por todas as questões sociais e por múltiplas identidades. Não podem ser reduzidas a um lugar.

A gente enfraquece aquilo que já é frágil”.(Anotações de campo do dia 23 de agosto de 2013).

O contraste de sentidos expostos durante as palestras foi evidente. Um olhar acadêmico não suficientemente esclarecedor, sobre a definição e utilidade da noção e perspectiva de gênero, em face de uma fala inspirada no dia-a-dia do I Juizado de Violência Doméstica e Familiar contra a Mulher (JVDFM) do Rio de Janeiro, que remarcava os limites do Judiciário ao se traduzir a noção de gênero para a linguagem jurídica, à luz de um corpo normativo voltado para a proteção das mulheres em situação de violência. 
Com efeito, a cientista social convidada ${ }^{15}$, referiu-se aos desafios da inserção do termo gênero no texto da LMP, remarcando o confortável que seria "falar da academia". Ela opta pela compreensão da questão do gênero como "fenômeno social que organiza as relações na sociedade, como estruturador e organizador, com o mesmo estatuto teórico das noções de classe e raça/etnia, em vez de entendê-lo como uma categoria equivalente à mulher ou à relação entre homens e mulheres" ${ }^{16}$.

Contudo, a acadêmica salientava que,

[...] a questão de gênero existe em função das desigualdades sociais e que sob essa visão as políticas para as mulheres têm de ser fortalecidas [...] estruturar um campo de políticas públicas para as mulheres, aperfeiçoar as relações entre os campos políticos, entre as diferentes políticas públicas, sem abandonar os centros especializados.

Somado ao anterior, no meio à descrição do mapa de fluxo da rede de atendimento especializado e articulado no Estado do RJ, uma afirmação foi pronunciada com marcada ênfase: "O sistema de justiça é que faz acontecer a $\mathrm{LMP}^{\prime 17}$, querendo significar que esta se tornaria eficaz só em função da atuação do Judiciário, ainda no contexto de articulação de políticas e de instâncias estatais. Ainda, para ilustrar sua fala, a expositora se utilizou de um gráfico que mostrava o "sistema de justiça", integrado pelo judiciário (TJ e JVDFM), a defensoria pública e o ministério público, como eixo da atuação em rede, quer dizer, como receptor e como suporte da atuação das demais instâncias da rede.

Em outro momento, entrevistado o ex-Juiz do JVDFM de Niterói (RJ), suas manifestações aludiram a uma "superposição de redes e fluxos": uma rede externa ao Judiciário, que interage com ele, e uma rede interna, no Judiciário, pertencente à esfera de atuação in situ, de cada JVDFM. Nesse contexto, sua fala aponta um exercício de diferenciação ou delimitação: o que pertence à esfera da atuação da rede externa ou da rede interna, como parte da própria política de gestão dos conflitos distribuídos ao JVDFM, realizando em face das duas redes de atuação, novos processos de ajuste e delimitação ${ }^{18}$.

Na primeira situação - rede externa -, o Juizado limitar-se-ia à função de encaminhar as partes envolvidas para os serviços de apoio externo disponibilizado pelo Município,

\footnotetext{
${ }^{15}$ Lília Guimarães Pougy, mestre em Serviço Social pela UFRJ e doutora em Ciências Sociais pela PUC-SP.

16 Da palestra "Questões de Gênero na Atualidade: A violência de gênero nas relações sociais e na agenda dos direitos humanos. Respostas do Estado brasileiro ao fenômeno social da violência de gênero".

17 Afirmação feita no 1 o painel do dia 30 de agosto de 2013, integrado por Cecília Soares (Psicóloga e Mestre em Psicossociologia pela UFRJ), Adriana Mota (Coordenadora Estadual do Pacto Nacional pelo Enfrentamento à Violência contra a Mulher) e Marcelle Lyra (Coordenadora da Rede de Serviços de Enfrentamento à Violência contra a Mulher), com as palestras "Redes de serviços especializados de atendimento à mulher: Suas características, funcionalidades e especificidades" e "Processo de construção, necessidade de atuação integrada. Apresentação do Fluxo da Rede Capital".

18 Um correlato possível desse modo de atuação estaria explicado por Viviana Zelizer (2011) através da noção de trabalho relacional ao descrever, na tradição jurídica anglo-saxã, como opera a intervenção judicial na resolução de conflitos em que intimidade e transações econômicas se entrecruzam.
} 
visando intervir mais adequadamente no conflito, e racionalizando o recurso à judicialização - segundo a visão do ex-Juiz entrevistado. No entanto, não seria a rede externa que determina a atuação do JVDFM. É o juiz que conduz e gerencia os limites da funcionalidade da rede externa, conforme os códigos do seu próprio subsistema.

Já na segunda situação - rede interna - além do exercício de enquadramento dos casos conforme o artigo 5o da LMP que, como descrito anteriormente, se depara com múltiplos obstáculos na tradução da categoria gênero para a linguagem jurídica,e ainda no marco das diretrizes de política judiciária ${ }^{19}$, emerge uma espécie de micropolítica judiciária, refletindo os critérios que para a compreensão e a gestão do conflito o Juiz constrói e prioriza de forma auto-referenciada no seu próprio espaço. Assim, dentro do Judiciário, cada JVDFM erige-se como um novo cenário de comunicações -subsistemas-autoreferenciados, voltados para a normalização do conflito.

Assim, por exemplo, no caso do JVDFM de Niterói, o ex-Juiz entrevistado salienta a necessidade de identificar, numa dinâmica auto-referenciada, "causas subjacentes" do conflito e indicadores de "pacificação" do conflito, levando em consideração a "natureza do conflito" - que para ele, é sempre "da ordem familiar" - e a conveniência ou necessidade de adotar uma certa atitude - o entrevistado utilizava-se comumente da expressão "parcimônia", por exemplo.

Esse específico entendimento, nortearia no caso, uma atuação que se serve da manutenção de uma rede interna conformada por serviços de apoio ligados à estrutura do Judiciário e ao JVDFM, que podem ou não coincidir com os elencados na LMP. Assim, enquanto a equipe técnica multidisciplinar se insere em decorrência direta da LMP e conforme as diretrizes da política judiciária subsequente, os critérios para se valer dela, dependem da gestão situada e particular do Juiz, quem ademais se utiliza de outros recursos internos, não ligados à LMP necessariamente - e inclusive rejeitados por ela comoseria o caso do centro de mediação.

Já quanto ao uso específico da equipe técnica multidisciplinar, ora para a avaliação psicossocial dos casos, ora para a realização dos grupos reflexivos para homens autores de violência, apreende-se, da entrevista realizada ao ex-Juiz e no decorrer da observação participante efetuada, que os critérios de encaminhamento para a equipe técnica dizem respeito àqueles aspectos que o Juiz identifica como relevantes para reforçar e suportar a "compreensão do conflito", baseada no código que ainda hoje prevalece no sistema jurídico, no que tange aos conflitos de gênero no âmbito doméstico e familiar, ainda que envolvam violência contra as mulheres, e a despeito do novo paradigma que a LMP buscou incorporar. Desse modo, códigos do sistema jurídico no qual se insere a LMP,

\footnotetext{
19 Destacam-se, no caso: o documento de "Padronização do Grupo Reflexivo dos Homens Agressores. Uniformização de Procedimentos para Estruturação, Funcionamento e Avaliação dos Grupos Reflexivos com Autores de Crimes de Situação de Violência Doméstica" e o "Manual de Rotinas e Estruturação dos Juizados de Violência Doméstica e Familiar contra a Mulher".
} 
próprios da compreensão deste tipo de conflitos como de natureza familiar, continuam a funcionar como critérios de comunicação com essa rede de apoio interna.

Em consequência, ao passo que em razão da especialização do juízo, este insere na sua estrutura um serviço técnico multidisciplinar, isto não implica em uma incorporação, na decisão jurídica, do entendimento psicossocial reproduzido nos relatórios da equipe técnica. Dito de outra maneira, enquanto a equipe avalia histórias de vida, processos de violência, redes familiares, impactos e expectativas individuais, bem como ponderações diversas quanto às relações de gênero, a definição jurídica do conflito que realiza o Juiz, se resume ao código procedimental próprio do sistema jurídico. No caso da justiça criminal âmbito no qual se insere a violência doméstica e a atuação dos JVDFM - esse código resume-se à definição de condutas típicas penalmente, é dizer, de atos ou fatos - não de processos relacionais ou subjetivos - e de definição de um motivo para a absolvição inclusive indiretamente por via da promoção da retratação da vítima, que leva à extinção da punibilidade - ou para a condenação - caso no qual opta-se pelo recurso à suspensão condicional da execução da pena de prisão.

No caso do Juizado observado, à medida que o código bipolar da racionalidade processual penal prevalece (absolvição / condenação, vítima / algoz), somado ao paradigma do garantismo penal e ao entendimento hegemônico da tradição jurídica que assigna aos conflitos de gênero um caráter de conflito familiar, não consegue se conciliar com as categorias sociais indefinidas que a LMP introduz, e uma vez que a demanda pelo enfoque integrador, articulador e multidisciplinar emerge como fio condutor da atuação pública voltada para a efetivação da LMP, o Juiz opta pela tradução e delimitação autoreferenciada dos recursos que na rede externa e na rede interna se disponibilizam.

Nesse ponto, a diferença conceitual entre estrutura e sistema decorrente da leitura de Luhmann que Juan Antonio García Amado realiza (2004) ganha relevância. A inserção de equipes multidisciplinares na organização do Judiciário, diz respeito à criação de condições de operabilidade do subsistema criado pela LMP, mas não resulta na incorporação de critérios psicossociais no subsistema jurídico sustentado pelas comunicações seletivas do específico JVDFM.

Os relatórios psicossociais produzidos pela equipe técnica multidisciplinar não são tomados nem incorporados na racionalidade da construção da decisão judicial. Eles dizem respeito a critérios que se comunicam com a rede de apoio externa, sem impactar na gestão judicial do conflito, sem incorporarem-se ao procedimento em si. As colocações técnicas da equipe permitem construir sugestões técnicas que, encaminhadas para o Juiz, este toma ou descarta, sempre de forma auto-referenciada.

Assim, ganha sentido a explicação que a teoria dos sistemas aponta: busca-se normalizar o conflito, não a construção de um consenso fático para sua resolução real - assunto que pertenceria ao meio social do qual emerge o conflito. Assim, o horizonte das expectativas traçadas pela LMP, referidas à transformação de padrões sócio culturais subjacentes à 
violência de gênero, à construção de equidade de gênero ou à remoção dos estereótipos de gênero que prejudicam as mulheres, é simplificado no sistema jurídico mediante procedimentos que se resumem à estabilização ou normalização dos conflitos, devolvendo-os, sem resolvê-los, ao meio social onde se produziram. Admite-se a impossibilidade de consenso fático entre os indivíduos:

[...] não pode ocorrer no seio de nenhum sistema um consenso que sirva como consenso social global. Esse consenso acabaria com a diferenciação funcional dos sistemas. Mais ainda, dentro de cada sistema seus elementos não se integram sobre a base do consenso, senão de uma bipolaridade alternativa que abarca por igual o polo positivo e o negativo: legal/ilegal, verdadeiro/falso, etc. O conflito não é destruidor do sistema, senão pressuposto de sua articulação. Dentro dos sistemas os conflitos são "normalizados", submetidos a esse padrão bipolar, e se evita assim seu contágio a todo o meio social.

[...] Tudo isto leva Luhmann a concluir que a legitimação das atuações de um sistema terá que ser produto do próprio sistema e não ser dada a partir de fora. Não poderá ser o consenso ou a conformidade com valores morais o que legitime uma decisão jurídica ou política, uma teoria científica, etc. Será o funcionamento normal dos mecanismos internos de cada um destes sistemas o que acarrete para suas atuações o reconhecimento social necessário. Aquilo sobre o que na sociedade se consente é o funcionamento dos sistemas, não as decisões ou os conteúdos que sigam desse funcionamento. (García, 2004, p. 327-328).

Por fim, as mesmas colocações permitem questionar a pretensão de construção de um corpo normativo híbrido configurado por medidas de natureza civil - o caso das medidas protetivas - e de natureza penal - delitos decorrentes de violência doméstica. A redução dessa nova complexidade, em cada JVDFM, limita-se ao ajuste auto-referenciado que opera cada Juiz. Assim, o apoio multidisciplinar da equipe técnica constitui um dado externo - embora inserido na estrutura do JVDFM - que nada diz respeito à simplificação jurídica dos critérios cíveis e penais que a LMP faz concorrer.

E na medida em que a estratégia comunicativa formulada pela própria LMP se resume à lógica processual criminal, é por essa via que as tensões e irritações são estabilizadas. Como exprimido pelo mesmo autor a partir da leitura de Luhmann:

Trata-se de um processo sem fim e sem finalidade. Não nasce em razão da consecução de um objetivo marcado por alguém situado fora do sistema e anterior ao mesmo. Explica-se unicamente em razão da função que o faz surgir no processo evolutivo: redução da complexidade. (García, 2004, 314).

E isso tudo, sem subordinação às condições subjetivas e existenciais dos indivíduos envolvidos no conflito: "[...] se esvanece a ideia do sujeito individual como centro de todo 
o sistema. [...] A sociedade e seus subsistemas, segundo Luhmann, não se compõem de indivíduos, senão de comunicações" (García, 2004, p. 325).

Também, porque não cabe afirmar o pertencimento integral dos indivíduos a um sistema. Eles "não formam parte dos sistemas sociais, senão de seu meio" e "nenhum indivíduo pertence por completo, como identidade total, a um sistema", enquanto "cada sistema funcional abarca sob sua perspectiva todos os indivíduos, mas não em sua integridade, senão só na dimensão de sua existência que importa para cada sistema" (García, 2004, p. 325).

Assim, as pretensões de integração, articulação, hibridismo jurídico e multidisciplinariedade colocadas na LMP, se esbarram com as dinâmicas próprias do funcionamento de subsistemas preexistentes. Seria o caso de conflitos familiares que envolvem violência doméstica contra a mulher que importam a ativação simultânea de gestão do conflito, em varas de família, em varas de violência doméstica, em varas criminais, em centros de mediação e na rede pública de atendimento em saúde e apoio terapêutico. Cada um deles funciona de modo auto-referenciado, demarcando seus próprios limites em relação aos demais subsistemas que o irritam, produzindo-se a inevitável fragmentação da gestão dos conflitos, conforme as dimensões existenciais dos indivíduos que são tomadas parcialmente, pelos diferentes subsistemas.

\section{Conclusão: um prognóstico pessimista nas estratégias jurídico - políticas para o enfrentamento à violência de gênero?}

As reflexões apresentadas, inspiradas na teoria dos sistemas sociais de Niklas Luhmann, parecem levar a um prognóstico pessimista quanto à instrumentalidade e eficácia das estratégias jurídico - políticas promovidas para o combate à violência de gênero. Estaríamos desembocando na evidencia de um fetichismo legal que nada diz respeito ao eficaz enfrentamento a esse problema social? Estaríamos optando pela ineficácia ou pelo escasso impacto das mobilizações feministas que têm se debruçado com grande esforço na luta por mudanças no Direito, enquanto instrumento de poder capaz de reproduzir os discursos androcêntricos e sexistas que banalizam a violência que afeta as mulheres? Estaríamos ensejando soluções simplistas de desjuridificação e de retorno ao âmbito privado como contexto privilegiado de tratamento dos conflitos que envolvem violência doméstica?

Diremos que não. Em realidade a proposta do presente trabalho seria a de chamar a atenção sobre um aspecto comumente negligenciado na formulação de políticas públicas no âmbito legal, em dois sentidos: por um lado, trata-se de estratégias que em geral desconsideram aspectos essenciais do funcionamento do sistema jurídico. Como lidar com o sistema, sem compreender os mecanismos de funcionamento do próprio sistema? 0 foco exclusivo nas alterações do conteúdo das leis, negligenciando a dinâmica de funcionamento do sistema de justiça, erige-se, conforme acima assinalado, como o maior obstáculo na produção de mudanças da linguagem jurídica. 
Concordamos com a leitura de Juan Antonio García Amado, no seu entendimento de que segundo Luhmann não se trata de pensarmos num sistema jurídico fechado ao ponto da cristalização e inviabilidade de mudanças internas. Não seria esse o alcance da chamada "autopoiesis" desenvolvida como categoria chave para compreender o funcionamento relativamente fechado e auto-referenciado do sistema jurídico, como sistema social prototípico (Luhmann, 1983 e 1985, p. 167 - 181). Pelo contrário, o que emerge como nó crítico de análise, é que a mudança parece ser viável, somente na medida da irritação e mudança dos mecanismos e critérios de seleção, por meio dos códigos pré-constituídos dentro do próprio sistema.

Não seria a mudança de conteúdos legais, sejam quais forem as novas categorias criadas por meio de novos dispositivos legais - como no caso, a noção de gênero - o que por si só viria a produzir transformações nas estratégias comunicacionais do Direito, e especificamente do sistema de justiça.

Um elo adicional parece ter sido esquecido: o do funcionamento do sistema que faz com que sejam ou não operacionalizados novos conteúdos normativos. Quer dizer, mais que interferir sobre as estruturas e corpos normativos, através apenas de conteúdos legais seja pela inserção de uma categoria das ciências sociais - gênero -, seja pela incorporação de outros saberes - multidisciplinaridade - que por sua vez pressupõe uma atuação em rede, torna-se essencial levar em conta aspectos peculiares do funcionamento do sistema jurídico, que precedem à vigência da Lei Maria da Penha, destacando-se sua dinâmica auto-referenciada. Ainda mais, sob o entendimento de que é essa dinâmica a que justamente garante a existência e manutenção do próprio sistema.

O mesmo diremos da intervenção na estrutura do Judiciário por via de alterações normativas que privilegiam a especialização, tanto de corpos normativos quanto de operadores - criação de juizados especializados, por exemplo - como estratégia exclusiva para alcançar um tratamento mais adequado dos conflitos de gênero.

Mostra-se, portanto fundamental acrescentar este critério de análise mediante pesquisas qualitativas com enfoque mais voltado para o processo autônomo de criação e recriação dos códigos de comunicação do próprio sistema e dentro dele. Completando o círculo de compreensão do fenômeno ou apreendendo-o em seu natural dinamismo: ao mesmo tempo em que múltiplas irritações são produzidas do meio externo para o sistema jurídico, dentro do próprio sistema provocam-se novos processos de redução da complexidade. Esse segundo estágio do processo tipicamente é analisado de maneira incipiente e justamente por isso ressaltamos a importância de enfocá-lo seriamente neste debate.

\section{BIBLIOGRAFIA}


Ardaillon, Daniele e Debert, Guita G (1987): Quando a vítima é mulher: análises de julgamentos de crimes de estupro, espancamento e homicídio. Brasília: Conselho Nacional dos Direitos da Mulher/Ministério da Justiça.

Campos, Carmen (2003): “Juizados Especiais Criminais e seu déficit teórico”, em Revista Estudos Feministas, vol. 11, n 1, Santa Catarina - UFSC, p. 155-170.

(2011): "Razão e Sensibilidade: teoria feminista do direito e Lei Maria da Penha", em Campos (org.): Lei Maria da Penha comentada em uma perspectiva jurídicofeminista. Rio de Janeiro: Lumen Juris.

Campos, Carmen e Carvalho, Salo (2011): "Tensões atuais entre a criminologia feminista e a criminologia crítica: a experiência brasileira", em Campos (org): Lei Maria da Penha comentada em uma perspectiva jurídico-feminista. Rio de Janeiro: Lumen Juris.

Conselho Nacional de Justiça (2010): Manual de Rotinas e Estruturação dos Juizados de Violência Doméstica e Familiar contra a Mulher. Disponível em: http://www.amb.com.br/fonavid/Documento Manual\%20Maria\%20da\%20Penha. pdf

Fraser, Nancy (2001): "Da redistribuição ao reconhecimento? Dilemas da justiça na era pós-socialista", em Souza (org.): Democracia hoje: novos desafios para a teoria democrática contemporânea. Brasília: EdUnB.

García Amado, Juan Antonio (2004): "A sociedade e o direito na obra de Niklas Luhmann", em Arnaud e Lopes (org.): Do sistema social à sociologia jurídica. Rio de Janeiro: Lumen Juris.

Luhmann, Niklas (1983 e 1985): Sociologia do direito. Rio de Janeiro: Ed. Tempo Brasileiro.

Maciel, Débora (2011): "Ação coletiva, mobilização do direito e instituições políticas: o caso da Campanha da Lei Maria da Penha", em Revista Brasileira de Ciências Sociais, Vol. 26, p. 97-112.

McCann, Michael (1999): Rights at work: pay equity reform and the politics of legal mobilization. Chicago: The University of Chicago Press.

Pasinato, Wânia e Santos, Cecília MacDowell (2005): Violência contra as mulheres e violência de gênero: notas sobre estudos feministas no Brasil. Disponível em: http://www.nevusp.org/downloads/down083.pdf.

Pasinato, Wania (2010): "Lei Maria da Penha: novas abordagens sobre velhas propostas. Onde avançamos?”, em Civitas: Revista de Ciências Sociais, v. 10, p. 216-232, 2010. 
(2011). "Avanços e obstáculos na implementação da Lei Maria da Penha", em Campos, Carmen Hein de (Org.). Lei Maria da Penha comentada em uma perspectiva jurídico-feminista, p. 119-142, Rio de Janeiro: Lumen Juris.

Pimentel, Sílvia et al. (1998): Estupro, crime ou cortesia: abordagem sóciojurídica de gênero. Porto Alegre: Fabris.

Piovesan, Flávia e Pimentel, Silvia (2002): Relatório Nacional Brasileiro Relativo aos anos de 1985, 1989, 1993, 1997 e 2001, nos termos do artigo 18 da Convenção sobre a Eliminação de todas as formas de Discriminação contra a Mulher. Brasília, MRE/MJ/SEDIM.

Reis Lavigne, Rosane (2009): “Lei Maria da Penha: o movimento de mulheres chega ao poder judiciário", em Cunha (org.): Direitos Humanos e Poder Judiciário no Brasil. Rio de Janeiro: Editora FGV, p. 145-241.

Rifiotis, Theophilos (2008): "Judiciarização das relações sociais e estratégias de reconhecimento: repensando a violência conjugal e a violência intrafamiliar", em Revista Katálisys, Vol. 11, no 2.

Rios, Roger Raupp (2012): “Comentário jurídico: Direito à diferença”, em Souza Lima (org.): Antropologia e Direito: Temas antropológicos para estudos jurídicos, p. 247259. Rio de Janeiro/Brasília: Contra Capa/Laced/ABA.

Senado Federal, (2013): Relatório da Comissão Parlamentar Mista de Inquérito da Violência contra a Mulher. Disponível em: http://www.senado.gov.br/atividade/materia/getPDF.asp?t=130748\&tp=1

Scott, Joan (1995): "Gênero: Uma categoria útil para a análise histórica", em Educação \& Realidade, Vol. 20, no2, p. 71-99.

Simião, Daniel (2000): O pulo do sapo: gênero e a conquista da cidadania em grupos populares. Curitiba: Expoente.

Smart, Carol (2010): "La teoría feminista y el discurso jurídico", em Birgin (comp.): El Derecho en el Género y el género en el derecho. Buenos Aires: Editorial Biblos.

Tribunal de Justiça do Estado do Rio de Janeiro (2012): "Padronização do Grupo Reflexivo dos Homens Agressores. Uniformização de Procedimentos para Estruturação, Funcionamento e Avaliação dos Grupos Reflexivos com Autores de Crimes de Situação de Violência Doméstica", em Direito em Movimento, Vol. 14, p. 405 - 427, disponível no site web da Escola da Magistratura do Estado do Rio de Janeiro: 
Revista Punto Género № 7. Mayo de 2017

ISSN 0719-0417 / 46 - 68

http://www.emerj.rj.gov.br/revistadireitoemovimento_online/edicoes/volum e14/volume14.pdf.

Zelizer, Viviana (2011): A Negociação da Intimidade. Petrópolis: Vozes. 